\title{
Oil Spills in Coastal Zones: Predicting Slick Transport and Weathering Processes
}

\author{
J. Antunes do Carmo ${ }^{1, *}$, J.L. Pinho ${ }^{2}$ and J.P. Vieira ${ }^{2}$ \\ ${ }^{I}$ IMAR-FCTUC, Department of Civil Engineering, University of Coimbra, Portugal \\ ${ }^{2}$ Department of Civil Engineering, University of Minho, Braga, Portugal
}

\begin{abstract}
This paper presents some considerations about environmental consequences of the spills and also about oil spill detection and control. Afterwards, it presents a computational structure that has been developed to forecast the time-space evolution of oil spills in marine environments. This structure was developed based on widely used mathematical formulations for oil spreading and weathering processes. It uses depth-averaged currents obtained from a two-dimensional and/or a quasi-three-dimensional hydrodynamic model, and net wave velocities obtained analytically. A Lagrangian transport model or, alternatively, a Eulerian transport model is used to predict the oil slick transport and spread. General characteristics of the computational structure and the results of its application to two real case studies - the "Cercal" accident on October 1994, and the "New World" tanker accident on December 1994 - are presented. Comparisons of numerical results with measured data are shown and a brief discussion about the computational structure performance is also presented.
\end{abstract}

Keywords: Coastal zones, oil spills, numerical simulation, case study.

\section{INTRODUCTION}

Petroleum products that enter the marine environment have distinct effects, according to their composition, concentration and the elements in the environment that are taken into consideration. Some effects can be related to transformations of the chemical composition of the environment and alterations in its physical properties, the destruction of the nutritional capital of the marine biomass, danger to human health, and changes in the environmental biological equilibrium.

The natural and atmospheric sources of pollution in the marine environment account for only a small percentage of total ocean pollution (around 16\%) when compared to the $37 \%$ attributed to urban and industrial loading and to the approximately $45 \%$ due to shipping (tank cleaning and unballasting) and oil tanker accidents [1]. A large portion of this pollution results from the failure to take due care in tank cleaning and unballasting operations.

Another aspect that must likewise not be neglected involves properly equipping ports with adequate residuereception facilities, since the waters contaminated with dirty ballast and the oily residues from ships' engine rooms represent around 300000 tons of oily residues spilled to sea every year.

Accidental oil tanker spills represent an annual contribution of approximately 400000 tons, most of which occur during routine loading, unloading and provisioning operations. Collision and running aground incidents are less frequent, but they involve greater losses and have more harmful consequences.

*Address correspondence to this author at the IMAR-FCTUC, Department of Civil Engineering, University of Coimbra, Portugal; Tel: 351239797 153; Fax: 351239797 152; E-mail: jsacarmo@dec.uc.pt
Residual waters from refineries and other coastal industries are a significant source of pollution. Other diffuse sources like burned (used) oils originating from the sewage and highway drainage systems must also be considered.

The mechanisms of toxic action depend on the petroleum's characteristics. The toxicity of the various fractions of the pollutants is directly related to the distilled products, on a short-term basis, and related to the slow-action products, on a long-term basis. It is also related secondarily to the products degraded either biologically, through the action of bacteria, or through physical-chemical processes.

Petroleum pollution can be detected through the modification of the environmental conditions and can be described by:

- transformations of the chemical composition of the environment and alterations in its physical properties;

- destruction of the biomass' nutritional budget; and

- changes in the environmental biological equilibrium.

From the physical point of view, hydrocarbons directly influence the marine environment, since gas transfer mechanisms are disturbed by the presence of a pollutant layer on the surface. Self-purification processes are thus reduced. These processes can be aggravated by the increased oxygen consumption by growing micro-organisms, depending on the quantity of biodegradable organic matter present. This oxygen deficit could even create conditions for anaerobic life, giving rise to the death and disappearance of certain species and permitting the fermentation of organic residues.

From a biological point of view, the environmental effects of oil are varied and complex. While some are immediately obvious, others only manifest themselves after a long period. The degree of the effect is therefore different, 
whether in the animal or in the plant kingdom. In the case of crude oil, the volatile components and the aromatic compounds are the most toxic.

In addition to possible direct intoxication resulting from the inhalation or ingestion of petroleum products, there is an indirect risk to humans from the consumption of certain marine animals (fish, crustaceans, shellfish, etc.) that have been in close contact with the oil.

The pollution's noxious effects can also be felt indirectly through its environmental and economic impacts: damage to biological resources (flora and fauna), affecting biodiversity; deterioration in seawater and shoreline quality, with negative effects on economic activities.

The first and hardest influences to gauge are those that take a broader view of the oceans as one of humanity's last resources. In a narrower sense, it is important to keep in mind that an oil spill affects all the people who directly or indirectly exploit marine resources, particularly those related to tourism, fishing and fish farming.

The Iberian coastal waters are noted for their intense oil tanker traffic and, as a consequence, the risk of an oil spill occurring in these coastal waters is high. The Prestige oil tanker disaster, in the Atlantic Ocean off the coast of Spain on November 19, 2002, when the vessel sank after leaking about 30000 tons of fuel oil, is just one example of an accident with detrimental environmental consequences for the Iberian coastal zone.
An accident with particularly severe damage for the touristic activities occurred in the Atlantic Ocean on December 28, 1989, with the "Aragon" tanker. The spillage of about 25000 tons of crude oil was detected at a distance $260 \mathrm{~km}$ north-east of Porto Santo (Madeira) island. The oil slick only reached Porto Santo 15 days after and severely polluted the island's East Coast. Fig. (1) shows Porto Santo beach three days after this accident.

Another accident occurred in the Atlantic Ocean on December 21, 1994, with the "New World" tanker (at coordinates $36^{\circ} \mathrm{N}$ and $13^{\circ} \mathrm{W}$, approximately). Field observations stopped at January 1, 1995, and no protection measures were planned; however, as numerical computations show (section 3.3) the pollutant cloud would reach Porto Santo 10 days after.

Clean-up operations, on the other hand, have elevated costs. As an example, the cost of cleaning up the black tide resulting from the 1994 spillage of 3000 tons of crude off Leixões (Porto, Portugal) exceeded € 50000.

In the following section are described some aspects of oils spills detection and control. Section "Numerical modelling of the behaviour and evolution of hydrocarbon spills at sea" details the computational framework, including its application on the simulation of two different oil spills accidents and comparisons between observed data and numerical results. Section "A discussion on strengths and weaknesses of numerical simulations" is devoted to an overall description on the strengths and weaknesses of numerical applications, including a suggestion for further investiga-
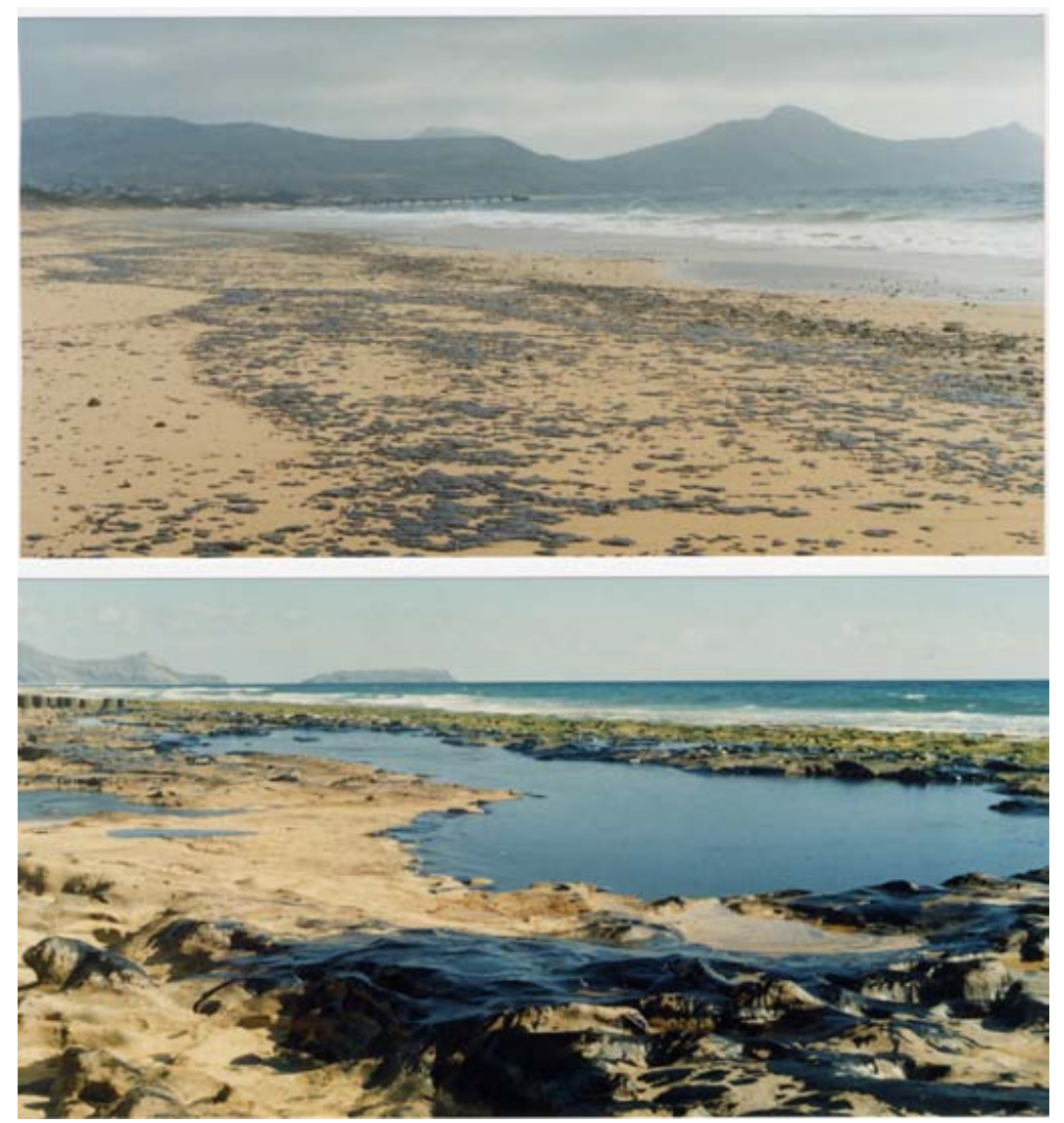

Fig. (1). Aspect of the Porto Santo (Madeira) beach as a consequence of the "Aragon" tanker accident on December 28, 1989 (January 1990). 
tion in this area. A final section summarizes the major conclusions.

\section{OIL SPILL DETECTION AND CONTROL}

In order to efficiently combat the permanent danger of marine pollution caused by hydrocarbon spills, it is extremely important, once a spill has been detected, to be able to predict both the discharge location and the transformations that the hydrocarbons undergo in time, quickly and precisely.

Remote sensing is a widely-used technique employed with considerable success to define the affected zones, to determine the extent of the spill and to help guidance for ships combating pollution. For that purpose, aerial detection sensors have been developed. However, under adverse meteorological conditions, they only provide sufficient information when used in combination with ships dully equipped. The most common sensor combination consists of thermal image cameras on the UV and IV wavelengths plus a lateral aerial radar (synthetic aperture radar). The first remote satellite sensors were launched in the early 70s (LANDSAT), and the Advanced High-Resolution Radiometer, launched at the end of the nineties, is still operational today.

These sensors are particularly efficient for monitoring sediments in suspension, since the clouds of pollutants are easily detectable. They do not, however, allow the corresponding concentrations to be determined. A system whereby samples are collected by ship provides more precise information about the thickness of the cloud, but has a very limited spatial coverage. The combination of these two detection resources (Radar and Ship) will essentially provide more precise information.

Under favourable conditions, the remote sensing technique is capable of defining the zones affected and the extent of the spills. Remote sensing data could also serve as entry data to verify the results obtained from predictive models of spill evolution. However, this technique is difficult to use in unfavourable atmospheric conditions, which are the most likely ones to prevail during accidents at sea.

Many countries in northern Europe use a combination of satellite sensors and airborne sensors for oil spill surveillance in the marine environment [2].

While space-borne radars (ERS-2 and RADARSAT-1) have a minimum spatial resolution of $9 \mathrm{~m}$, airborne radars (typical SLAR and SAR) can have a minimum resolution of 1-3 m [3]; however, airborne sensors are only used for short term or tactical response. Some recently launched spaceborne sensors, like RADARSAT-2, have improved spatial resolution.

As referred in Jha, Levy, and Gao [3], sensors capturing a synoptic view of the area are desirable and will help in monitoring the oil spill over a large area. This study also shows that radar sensors (SAR and SLAR) can capture a large area and are very useful for providing general view of affected area.

Containing operations at sea generally involve the use of floating barriers that can be used to confine, concentrate or manage oil slicks, as shown in Fig. (2).

Various types of collection equipment may be used, the choice of which will depend on the following factors: spill location and dimension, movement of the spill, meteorological conditions, hydrographic conditions, and protection priorities.

The elimination of surface hydrocarbons is one of the main goals of pollution-control actions and various methods have been tried to tackle the problem. The physical removal

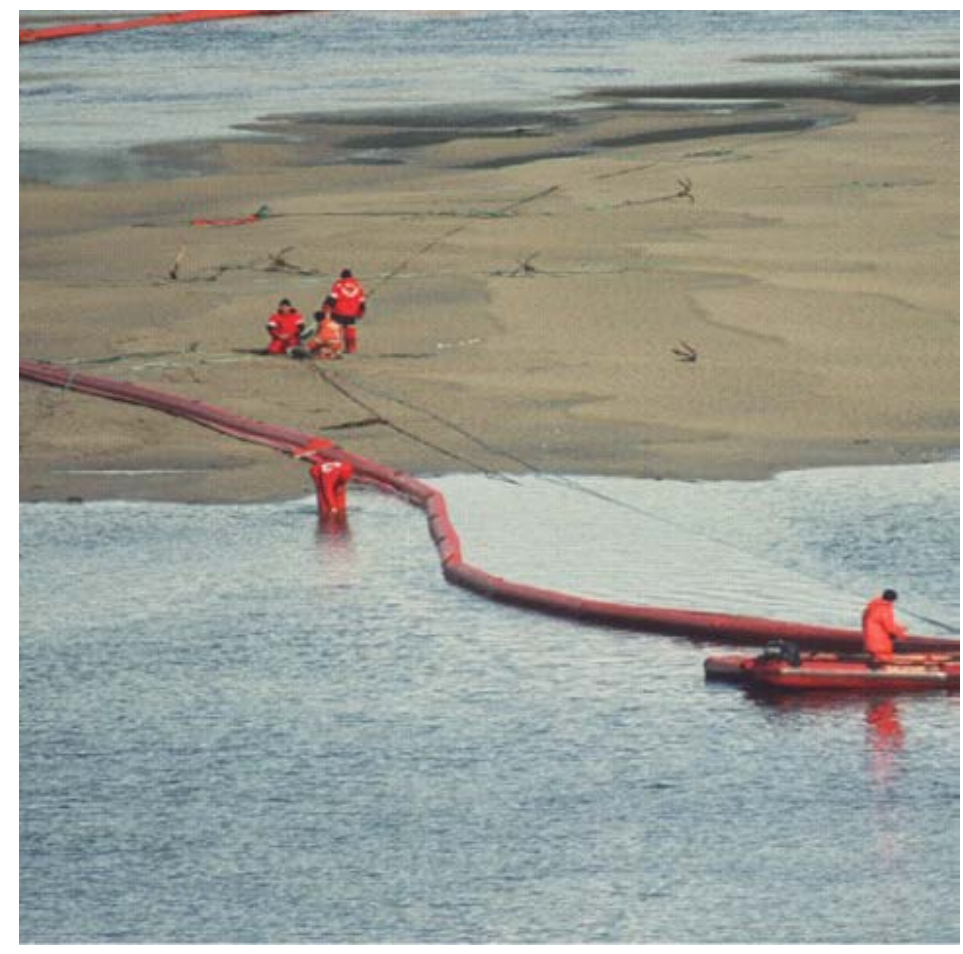

Fig. (2). Surface controlled net for collecting the crude and oil adsorbing elements (November 2002). 
of the oil is generally considered preferable to chemical removal, since it does not introduce additional substances into the marine environment, involves a smaller quantity of irrevocably lost hydrocarbons and permits the reuse of the collected products.

\section{NUMERICAL MODELLING OF THE BEHAVIOUR AND EVOLUTION OF HYDROCARBON SPILLS AT SEA}

Spreading and weathering processes (i.e. evaporation, dissolution, dispersion into the water column, emulsification, changes in viscosity and density) can be simulated by numerical models based on mathematical formulations that describe these processes, according to their physical and chemical properties.

It is important to keep in mind that the numerical model to be used should be sufficiently simple and fast, from a computational point of view, to allow information to be gathered in real time, and due to the following reasons:

- forecasts for real accidents requires fast responses in order to be helpfully in the protective measures implementation;

- the evolution of hydrocarbon spills depends on environmental processes and factors that are still poorly understood and whose mathematical description is complicated, and depends on empirical hypotheses; and

- in real accident situations, important factors are generally unknown, such as the real quantity of oil spilt and some of its properties.

In preventive terms, numerical models could even be the only method of planning the implementation of means of combating pollution at sea. In the meantime, predictions provided by these models should, whenever possible, be accompanied by direct observations. In this way, the model's predictions will help to guide direct observations, and, with the necessary precautions, direct observation will permit the recalculation of prediction data from that point on. Among the various useful works in this field are [4-17].

\section{Mathematical Formulations}

Most oil spill transport models have adopted a Lagrangian description. However, it is likely that Eulerian models will be used more frequently in the future as they need to be coupled with the (Eulerian) hydrodynamic models and (Eulerian) meteorological models of the lower atmospheric boundary layer.

In this work, numerical models for oil spill simulation use the hydrodynamic data required for either a Lagrangian or a Eulerian transport approach to describe the spreading and weathering processes. Hydrodynamic data are obtained by applying the Saint-Venant or shallow-water equations, using either a two-dimensional (2DH) or a quasi-threedimensional (quasi-3D) form of the equations.

\section{Hydrodynamic Models}

A 2DH hydrodynamic model is implemented using a computer program based on the finite element method [18], and a quasi-3D (hydrostatic approximation) hydrodynamic model is developed using a finite difference hydrodynamic model, which corresponds to a modified version of the POM-Princeton Ocean Model [19,20]. The 2DH model is used in situations where the water flow does not exhibit a significant vertical variation, and the quasi-3D hydrodynamic model is used to calculate the surface water currents when a significant vertical variation is associated with the water flow pattern. The $2 \mathrm{DH}$ model equations are:

$$
\begin{aligned}
& \frac{\partial \eta}{\partial t}+\frac{\partial[(h+\eta) U]}{\partial x}+\frac{\partial[(h+\eta) V]}{\partial y}=0 \\
& \frac{\partial U}{\partial t}+U \frac{\partial U}{\partial x}+V \frac{\partial U}{\partial y}=+f V-g \frac{\partial c}{\partial x}-\frac{g}{\tilde{n}} \frac{\partial \tilde{n}}{\partial x} \frac{h+c}{2}+ \\
& +\frac{\tilde{n}_{a}}{\tilde{n}} \frac{k W^{2} \cos \varphi}{h+c ̧}-\frac{g U \sqrt{U^{2}+V^{2}}}{(h+c) C^{2}}+\frac{\stackrel{\circ}{\tilde{n}}}{\left(\frac{\partial^{2} U}{\partial x^{2}}+\frac{\partial^{2} U}{\partial y^{2}}\right)} \\
& \frac{\partial V}{\partial t}+U \frac{\partial V}{\partial x}+V \frac{\partial V}{\partial y}=-f U-g \frac{\partial \eta}{\partial y}-\frac{g}{\rho} \frac{\partial \rho}{\partial y} \frac{h+\eta}{2}+ \\
& +\frac{\rho_{a}}{\rho} \frac{k W^{2} \operatorname{sen} \varphi}{h+\eta}-\frac{g V \sqrt{U^{2}+V^{2}}}{(h+\eta) C^{2}}+\frac{\varepsilon}{\rho}\left(\frac{\partial^{2} V}{\partial x^{2}}+\frac{\partial^{2} V}{\partial y^{2}}\right)
\end{aligned}
$$

where $x$ and $y$ are the horizontal Cartesian coordinates, $t$ is the time, $U$ and $V$ are the vertical average of the horizontal velocity components, $h$ is the water depth, $\eta$ is the water surface elevation, $f$ is the Coriolis parameter, $\rho$ is the water density, $\rho_{a}$ is the air density, $k$ is the wind-stress coefficient, $W$ is the wind velocity at $10 \mathrm{~m}$ above the water surface, $\varphi$ is the wind direction, $C$ is the Chezy coefficient and $\varepsilon$ is the turbulent viscosity coefficient.

The quasi-3D model used is based on the Princeton Ocean Model [21]. Although computing explicitly the three velocity components at various levels, this is called a quasi$3 \mathrm{D}$ model due to the hydrostatic approximation and also due to the numerical technique implemented, where the vertically integrated equations are separated from the vertical structure equations, as explained below.

It contains a basic improvement whereby the external model is calculated using a finite element method technique to enhance its overall performance when applied to geometrically complex problems in which specific boundary conditions are considered. The following mass and momentum conservation equations are solved:

$$
\begin{aligned}
\frac{\partial \eta}{\partial t}+\frac{\partial}{\partial x}(u H)+\frac{\partial}{\partial y}(v H)+\frac{\partial w}{\partial \sigma}=0 & \\
\frac{\partial}{\partial t}(u H)+\frac{\partial(u u H)}{\partial x} & +\frac{\partial(v u H)}{\partial y}+\frac{\partial}{\partial \sigma}(w u)-f v H \\
& =-H P_{1}+\frac{\partial}{\partial \sigma}\left(\frac{K_{M}}{H} \frac{\partial u}{\partial \sigma}\right)+H F_{1} \\
\frac{\partial}{\partial t}(v H)+\frac{\partial(u v H)}{\partial x} & +\frac{\partial(v v H)}{\partial y}+\frac{\partial}{\partial \dot{o}}(w v)+f u H \\
& =-H P_{2}+\frac{\partial}{\partial \dot{o}}\left(\frac{K_{M}}{H} \frac{\partial v}{\partial \dot{o}}\right)+H F_{2}
\end{aligned}
$$

where $\sigma$ is the sigma vertical coordinate, $u$ and $v$ are the horizontal velocity components, $w$ is the transformed vertical 
velocity (physically, $w$ is the velocity component normal to sigma surfaces), $H=h(x, y)+\eta(x, y, t)$ is the total depth, $h(x, y)$ is the bottom topography, $f$ is the Coriolis parameter, $P_{1}$ and $P_{2}$ are the horizontal pressure gradient terms, $F_{1}$ and $F_{2}$ are the horizontal diffusion terms, and $K_{M}$ is the vertical kinematic viscosity.

In terms of computational efficiency, the vertically integrated equations (external mode) are separated from the vertical structure equations (internal mode). This technique, known as mode splitting [19] permits the calculation of the free surface elevation with little sacrifice in computational time by solving the velocity transport separately from the three-dimensional calculation of the velocity.

The external mode calculation results in updates for surface elevation, $\eta$, and the vertically averaged velocities, $U$ and $\mathrm{V}$. The internal mode calculation results in updates for $\mathrm{U}, \mathrm{V}$ and other quantities. A more detailed description of POM model can be found in [19]. is:

The transformation of $w$ to the Cartesian vertical velocity

$$
W=w+u\left(\sigma \frac{\partial H}{\partial x}+\frac{\partial \eta}{\partial x}\right)+v\left(\sigma \frac{\partial H}{\partial y}+\frac{\partial \eta}{\partial y}\right)+\sigma \frac{\partial H}{\partial t}+\frac{\partial \eta}{\partial t}
$$

\section{Transport Model}

The surface transport of the pollutant oil mass is obtained through,

$$
\vec{U}_{s}=\vec{U}_{c}+\vec{U}_{\text {wave }}+C_{w} D \vec{W}
$$

where $\vec{U}_{s} \equiv\left(U_{s}, V_{s}\right)$ are the final velocity components resulting from the depth-averaged current (2D model) or from the surface current (3D or quasi-3D model), $\vec{U}_{c} \equiv(U, V)$, obtained using anyone of the hydrodynamic models described above, the net wave current velocity $\vec{U}_{\text {wave }} \equiv\left(U_{\text {wave }}, V_{\text {wave }}\right)$, and the wind velocity at $10 m$ above the sea level $\vec{W} \equiv\left(U_{w}, V_{w}\right)$. When the wind effect is indirectly considered, through the hydrodynamic models, the last term of eq. (8) is neglected. $C_{w}$ is the wind drift factor, usually taken between 0.025 and 0.035 (commonly 0.0315), $D$ is the transformation matrix which allows introducing a deviation angle [16]:

$$
D=\left\{\begin{array}{cc}
\cos \theta & \sin \theta \\
-\sin \theta & \cos \theta
\end{array}\right\}
$$

where $\theta=40^{\circ}-8 \sqrt[4]{U_{w}^{2}+V_{w}^{2}}$ when $0 \leq|\vec{W}| \leq 25 \mathrm{~m} / \mathrm{s}$ and $\theta=0$ when $|\vec{W}|>25 \mathrm{~m} / \mathrm{s}$.

Although not used in this study, a wave formulation is included in the model to take into account its contribution, according to eq. (8). The wave action could be particularly important in coastal zones. The net wave current velocity at depth- $z$ below the mean surface, $\vec{U}_{\text {wave }} \equiv\left(U_{\text {wave }}, V_{\text {wave }}\right)$, is associated with the free surface wave motion. According to
Stokes second order theory, the mass transportation velocity for a regular wave train is (see also [16]),

$\vec{U}_{\text {wave }}=\frac{k \omega H_{s}^{2}}{8 \sinh ^{2}(k d)} \cosh [2 k(z+d)]$

where $\omega$ is the angular frequency ( $2 \pi /$ wave period $), k$ is the wave number ( $2 \pi$ /wave length $), H_{s}$ is the wave height and $d$ is the water depth. In the model, the significant wave height and the peak frequency are used to evaluate transportation velocity during the associated seastate.

The new mass centre coordinates $(x, y)$ at time $t+\Delta t$ are obtained through the following Lagrangian model,

$x^{t+\Delta t}=x^{t}+\Delta t U_{s}$
$y^{t+\Delta t}=y^{t}+\Delta t V_{s}$

Alternatively, instead of model (11), the following Eulerian surface oil slick transport eq. (12) is used, which is a mass conservation equation for the surface oil layer:

$\frac{\partial C}{\partial t}+\frac{\partial}{\partial x}\left(U_{s} C\right)+\frac{\partial}{\partial y}\left(V_{s} C\right)-\frac{\partial}{\partial x}\left(E_{x} \frac{\partial C}{\partial x}\right)-\frac{\partial}{\partial y}\left(E_{y} \frac{\partial C}{\partial y}\right)+k_{C} C=0$

where, $C=\rho \delta$ is the local concentration of surface oil, $t$ is time, $\rho$ is the local mass density of oil, $\delta$ is the local thickness of the oil layer, $E_{x}$ and $E_{y}$ are the local dispersion coefficients in the $x$ and $y$ direction, respectively, and $k_{C}$ is the local mass transfer rate from source/sink processes. This equation is solved numerically using a modified version of the RMA4 computer program [20].

\section{Spreading and Weathering Model}

The physical and chemical changes that spilled oil undergoes are collectively known as "weathering". Although the individual processes causing these changes may act simultaneously, their behaviour importance varies with time. Together they affect the behaviour of the oil and determine its ultimate fate. These processes are illustrated in Fig. (3) for a spill of a typical medium crude oil under moderate sea conditions.

This figure gives an idea about the scale and duration time of the main processes involved. Spreading, transport, evaporation and dissolution-dispersion are clearly the main important phenomena that occur immediately after the accident. The biodegradation process will be important and it will predominate after the first week.

To be effective on the implementation of measures to restraint and prevention contamination is essential act immediately after the occurrence of the accident, and therefore on the first processes involved.

The oil spreading and weathering processes can be modelled considering the overall effects of evaporation, vertical dispersion (volume and area variation), emulsification, viscosity and density changes.

The slick is assumed to be approximately circular with a spatially variable thickness. The oil is to spread under the influence of five forces: spreading forces are gravity and net surface tension, retarding forces are inertia, internal viscous 


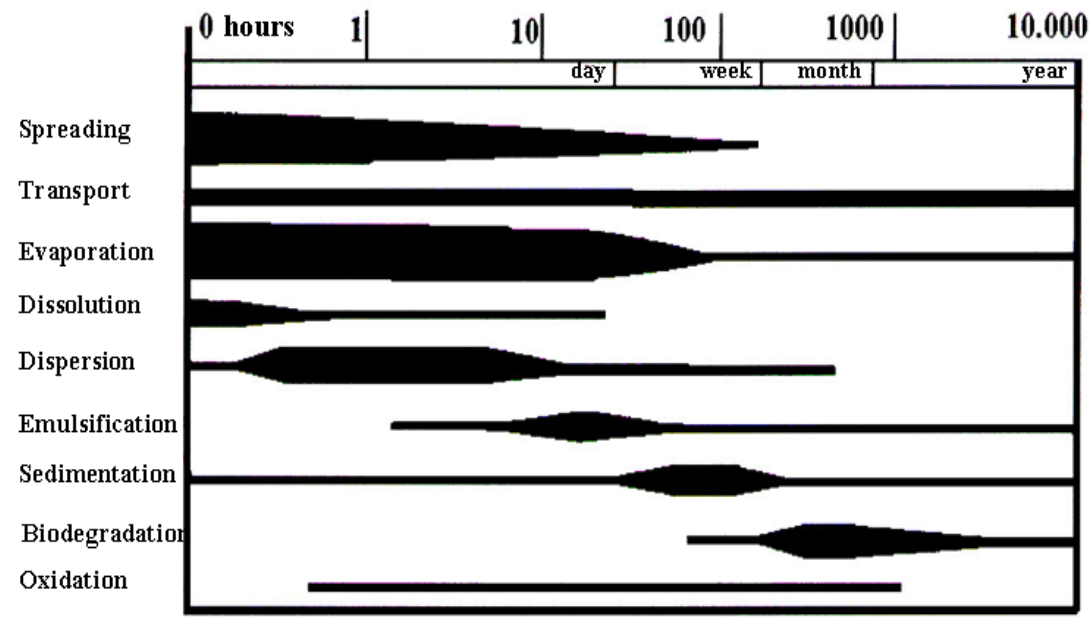

Fig. (3). Schematic evolution of the weathering processes with time [22].

force and interfacial (oil-water) viscous force. The acceleration of the edge of the oil slick is derived from the dynamic equilibrium of an elementary sector and reads:

$$
\begin{aligned}
\frac{d^{2} R}{d t^{2}}= & \frac{3 g V \Delta}{2 \pi R^{3}}+\frac{3 \pi \tau R}{\rho_{o} V}+\frac{1}{R}\left(\frac{d R}{d t}\right)^{2} \\
& -2.628 \frac{\rho_{w} \sqrt{v_{w}}}{\rho_{o} V}\left(R \frac{d R}{d t}\right)^{1.5}-3 v_{o} \frac{1}{R^{2}} \frac{d R}{d t}
\end{aligned}
$$

where $d^{2} R / d t^{2}$ is the acceleration of the edge of the slick, $d R / d t$ is the spreading rate and $R$ is the radius of the slick, $g$ is the gravity acceleration, $V$ is the total volume of the surface slick (oil and emulsion), $\rho_{\mathrm{o}}$ and $v_{\mathrm{o}}$ are the density and the kinematic viscosity of the oil, $\rho_{w}$ and $v_{w}$ are the density and the kinematic viscosity of the sea water, $\Delta=\left(\rho_{w}-\right.$ $\left.\rho_{o}\right) / \rho_{w}$, and $\tau$ is the net surface tension.

This equation is solved using a numerical method based on the Runge-Kutta method, taking into account the following initial conditions:

$$
R_{0}=K \sqrt{V_{o 0}} ; \frac{d R}{d t}_{t=0}=0.65 \sqrt{\Delta g}
$$

where $K=1 \mathrm{~m}^{-1 / 2}$ and $V_{o 0}$ is the initial spilt oil volume $\left(\mathrm{m}^{3}\right)$.

The evaporative loss fraction $\left(F_{e}\right)$ of a given hydrocarbon is described by the following equation [23]:

$\frac{d F_{e}}{d t}=\frac{K A_{o}}{V_{o}} \exp \left[A-\frac{B}{T}\left(T_{0}+T_{G} F_{e}\right)\right]$

where $K=2.5 \times 10^{-3} W^{0.78}, T$ is the product temperature $\left({ }^{\circ} K\right)$, $T_{0}$ is the initial temperature (when $F_{e}=0$ ), $A=6.3, B=10.3$, $T_{G}$ is the distillation curve gradient $\left({ }^{\circ} K\right), \mu$ is the dynamic viscosity $(c P), A_{o}$ is the oil slick area $\left(\mathrm{m}^{2}\right)$, and $V_{o}$ is the oil volume $\left(\mathrm{m}^{3}\right)$.

Vertical dispersion losses are modelled considering the rate proposed by [24]:

$$
Y_{d}=\frac{0.11(W+1)^{2}}{1+50 \mu^{1 / 2} \delta \gamma_{o w}}
$$

where $W$ is the wind velocity at $10 \mathrm{~m}$ above the sea level $(\mathrm{m} / \mathrm{s}), \boldsymbol{\mu}$ is dynamic viscosity $(c P), \delta$ is the pollutant slick thickness $(\mathrm{cm})$, and $\tilde{a}_{o w}$ is the oil-water surface stress (dyne/cm).

Taking the previous formulations for the oil losses, the volume variation can be expressed by (considering $V_{o 0}$ the initial oil volume):

$\frac{d V_{o}}{d t}=-V_{o 0} \frac{d F_{e}}{d t}-Y_{d} V_{o}$

The area rate growth is modelled using the following expression [24],

$\frac{d A_{s}}{d t}=K_{1} A_{s}^{-1} V^{4 / 3}$

where $K_{1}$ is a constant with default value of $150 \mathrm{~s}^{-1}, A_{s}$ is the superficial area of slick $\left(m^{2}\right)$, and $V=V_{o} /(1-Y)$ is the total volume of the surface slick at a given time $\left(\mathrm{m}^{3}\right)$, where $Y$ is the rate of incorporation of water into an oil slick.

Note that $A_{o}$ in eq. (15) is calculated through eq. (18) considering $V_{o}$.

Emulsification (fractional in water content, $Y$ ) is modelled by means of the expression,

$\frac{d Y}{d t}=K_{e m}(W+1)^{2}\left(1-\frac{Y}{Y^{F}}\right)$

where $K_{e m}=2.0 \times 10^{-6}$ for light oil or $4.5 \times 10^{-6}$ for weight oil, $W$ is the wind velocity at $10 \mathrm{~m}$ above the sea level $(\mathrm{m} / \mathrm{s})$, and $Y^{F}$ is the parameter corresponding to the final water volume fraction and depending on the oil type. $Y^{F}$ is equal to 0.70 for crude and heavy fuel oils and about 0.25 for light fractions. The gasoline, the kerosene and combustibles as diesel do not present emulsification [13].

The result of emulsification is not only a large increase in volume ( 3 to 4 times the volume of the original stabilized oil), but also a significant increase in the density and a very 
large increase in viscosity, due to mousse formation, which may be computed by $\mu=\mu_{0} \exp \left[2.5 Y /\left(1-Y^{F} Y\right)\right], \mu_{0}$ being the parent oil viscosity $\left(\mu_{0}=224 A^{1 / 2}\right.$, where $A=$ asphaltene content, \%). Evaporation also causes increases in both viscosity (which may be computed by $\mu=\mu_{0} \exp \left[C_{\mu} F_{e}\right]$ ) and density.

Changes in dynamic viscosity and density are modelled by the following expressions:

$$
\begin{aligned}
& \frac{d \mu}{d t}=C_{\mu} \mu \frac{d F_{e}}{d t}+\frac{2.5 \mu_{0}}{\left(1-Y^{F} Y\right)^{2}} \frac{d Y}{d t} \\
& \rho_{e}=Y \rho_{w}+(1-Y)\left(\rho_{o}+Y^{F} F_{e}\right)
\end{aligned}
$$

where $C_{\mu}$ is the mechanical oil rate recovery time. $C_{\mu}=1$ (gasoline) to 15 (heavy crude oils).

A numerical tool based on the Runge-Kutta method was developed to solve the system of eqs. (15), (17), (18), (19) and (20).

\section{"Cercal" Accident}

On the $2^{\text {nd }}$ October 1994 the Panamanian oil tanker "Cercal" struck a rock while entering the harbour of Leixões Porto (Portugal), releasing about 2500 tons of crude oil (Arabian Light) into the sea. Fig. (4) shows a satelliteacquired image two days after the accident. The spill could be seen floating along the coast and out to sea. The coastal city of Porto, lying near the centre of the oil spill, appears as a cluster of white dots. The rainy and foggy weather prevailing in that region of Portugal on the date of the accident made it very difficult to evaluate the spill from an aircraft. However, thanks to the all-weather capabilities of the satellite instrument it was possible to acquire this very useful scene through the cloud cover. The Portuguese authorities monitored the accident and some laboratory work was carried out to analyse the physical properties of the crude oil. Data on the oil slick position, its area and volume, and the mean daily wind velocity and direction are presented in Table $\mathbf{1 .}$

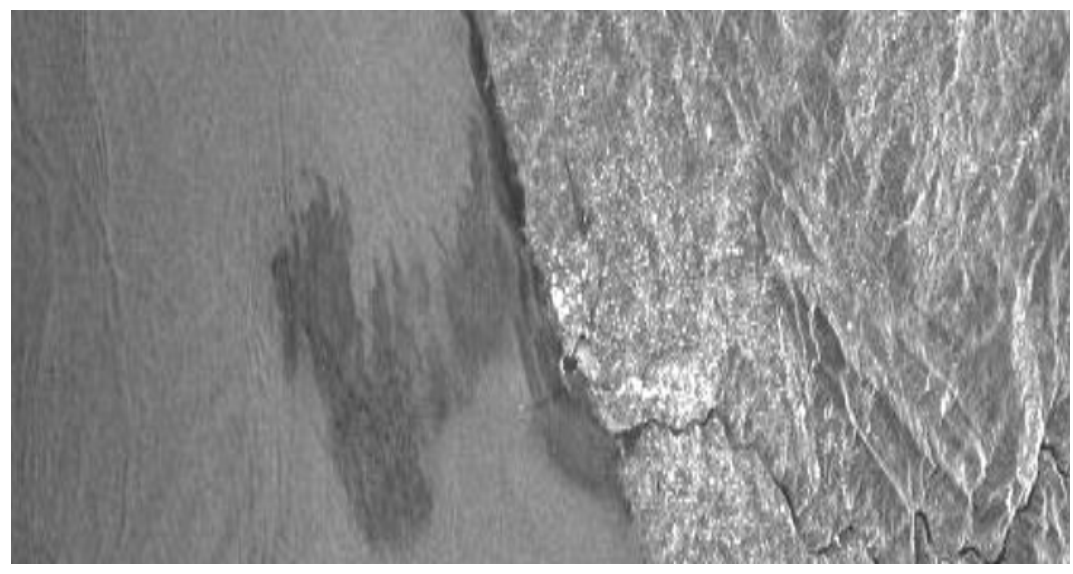

Fig. (4). Satellite-acquired image two days after the Cercal accident at the Leixões - Porto harbour (October 4, 1994).

Table 1. Changes in the Position (24h Intervals, Approximately), Volume and Geometry of the Pollutant Slick from the "Cercal" Accident, and Wind Characteristics [10]

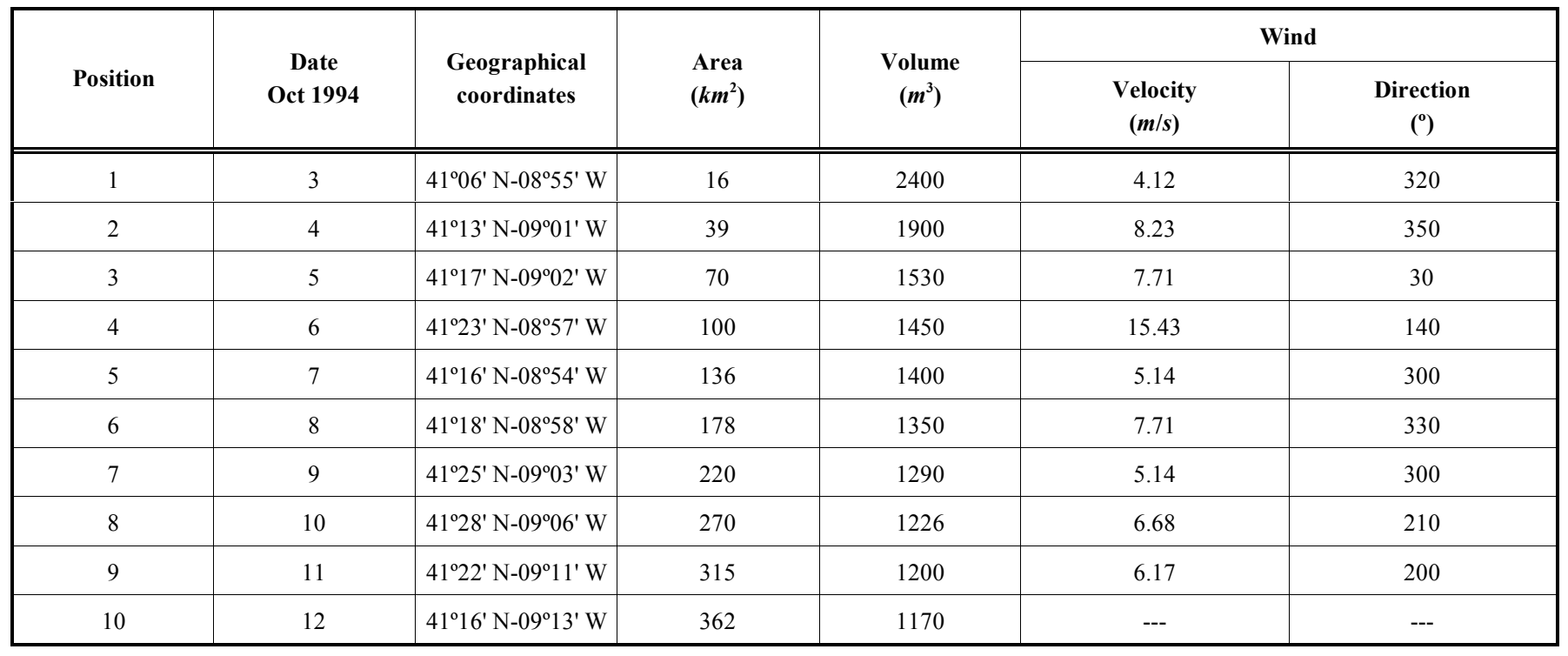


The first simulation only considers the wind action (without tide currents), with a 0.030 constant value for the wind drift factor $C_{w}$, the transport model (8)-(11), the spreading model (13)-(14), and eqs. (15)-(21) to obtain the oil spill evolution properties. The following crude oil parameters: $\rho=$ $857 \mathrm{~kg} \mathrm{~m}^{-3}, v\left(\right.$ at $\left.25^{\circ} \mathrm{C}\right)=6.30 \mathrm{cSt}, \mathrm{Y}^{F}=65 \%, T_{0}=292^{\circ} \mathrm{K}, T_{G}$ $=624{ }^{\circ} \mathrm{K}$ and $\gamma_{o w}\left(\right.$ at $\left.20{ }^{\circ} \mathrm{C}\right)=0.0309 \mathrm{Nm}^{-1}$ have been assumed.

This accident simulation starts at coordinates $41.16^{\circ} \mathrm{N}$ and $8.92^{\circ} \mathrm{W}$. Comparisons between the measured and simulated (continuous numbered black line) results are shown in Fig. (5) and Table 2. Maximum deviations in the coordinates are less than one mile, about 0.75 miles.

As tide currents at the accident site could play an important role in the oil transport process, a second simulation of this accident was performed to analyse their influence and also to test the Eulerian surface oil slick transport model [eq. (12)].
The previous results are then compared with those obtained by a computational structure consisting of the hydrodynamic model (1)-(3) to obtain the depth-averaged current velocities, the transport model (8)-(10) and (12), and eqs. (15)-(21) to simulate the oil spill evolution properties.

The 2DH hydrodynamic model (1)-(3) was used to quantify the tide currents' velocity at the northern Iberian Peninsula coastal zone during the accident. Fig. (6) shows the geographical extent, the finite element mesh (with 5294 quadratic triangular elements) and the bottom topography.

A hydrodynamic simulation was carried out imposing predicted tide water surface elevations [25] at the open ocean boundary Fig. (7). Since there was no data available for model calibration and validation purposes (for this simulation), its parameters were established taking values used in similar studies. Fig. (8) displays the instantaneous maximum tide current velocities (during ebb and flood) at the accident area.

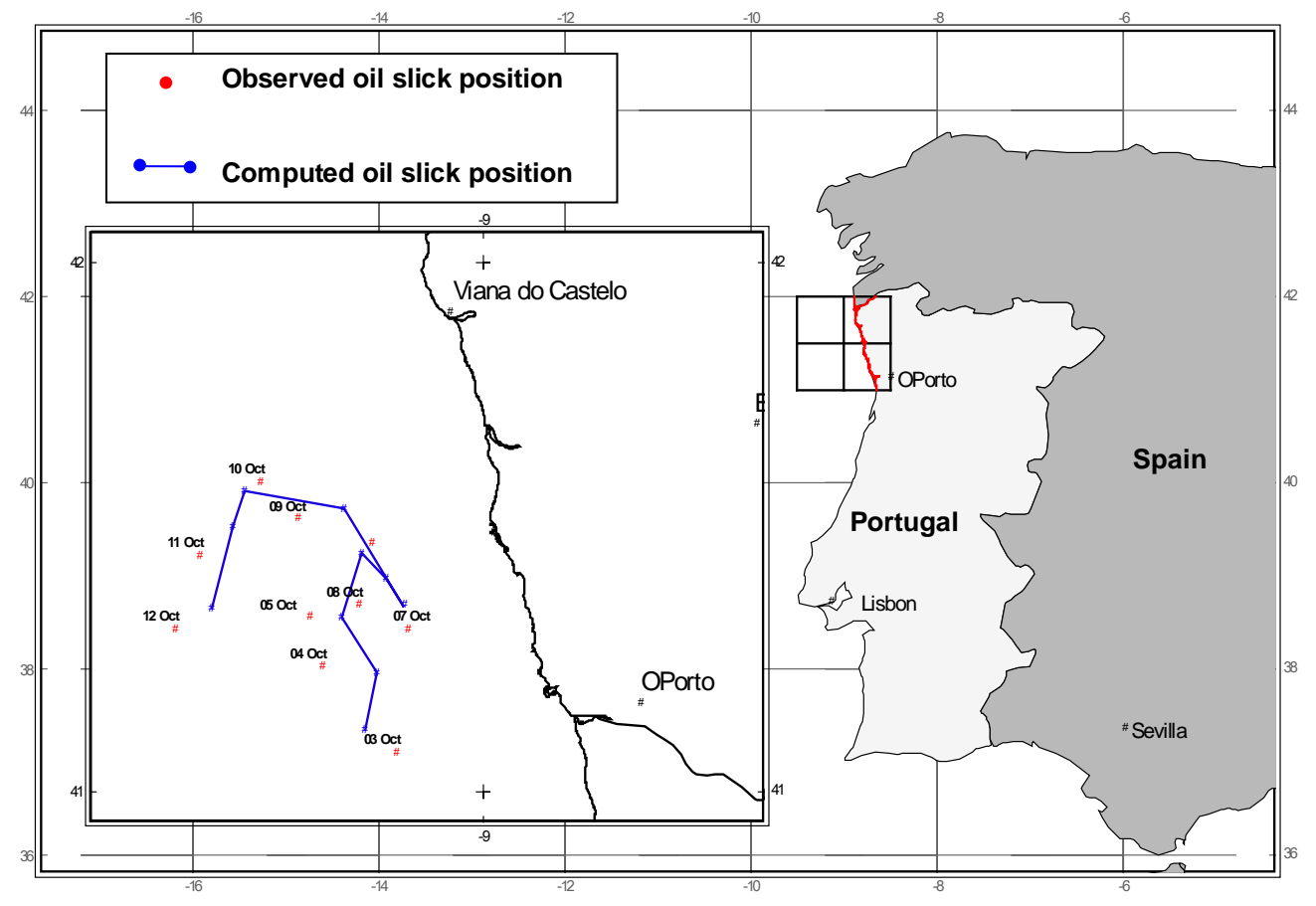

Fig. (5). Spatial and temporal evolution of the spill from the N/T "Cercal" [9].

Table 2. Volume and Geometry Changes of the Pollutant Cloud from the N/T "Cercal" [9-10]

\begin{tabular}{|c|c|c|c|c|c|c|c|c|}
\hline Day & $\begin{array}{c}\text { Volume } \\
\left(m^{3}\right)\end{array}$ & $\begin{array}{c}\text { Volume } \\
\left(m^{3}\right)\end{array}$ & $\begin{array}{c}\text { Relative } \\
\text { Error }\end{array}$ & $\begin{array}{l}\text { Area } \\
\left(\mathrm{km}^{2}\right)\end{array}$ & $\begin{array}{l}\text { Area } \\
\left(\mathrm{km}^{2}\right)\end{array}$ & $\begin{array}{c}\text { Relative } \\
\text { Error }\end{array}$ & $\begin{array}{c}\text { Radius } \\
(\boldsymbol{K m})\end{array}$ & $\begin{array}{c}\text { Thickness } \\
(\mathrm{mm})\end{array}$ \\
\hline $3-\mathrm{Oct}$ & 2400 & 2335 & -2.7 & 16 & 15.5 & -3.1 & 2.222 & 0.1506 \\
\hline 5-Oct & 1530 & 1457 & -4.8 & 70 & 68.65 & -1.9 & 4.572 & 0.0222 \\
\hline 9-Oct & 1290 & 1256 & -2.6 & 220 & 215.56 & -2.0 & 8.283 & 0.0058 \\
\hline 11-Oct & 1200 & 1199 & -0.1 & 315 & 308.5 & -2.1 & 9.91 & 0.0038 \\
\hline
\end{tabular}


a)

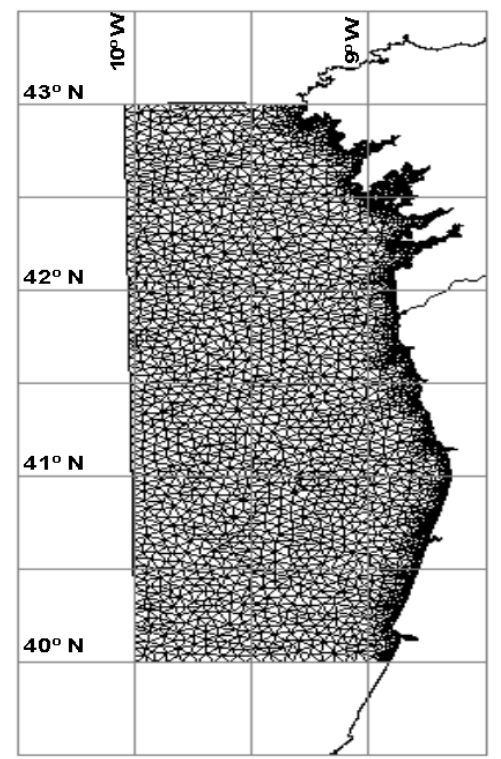

b)

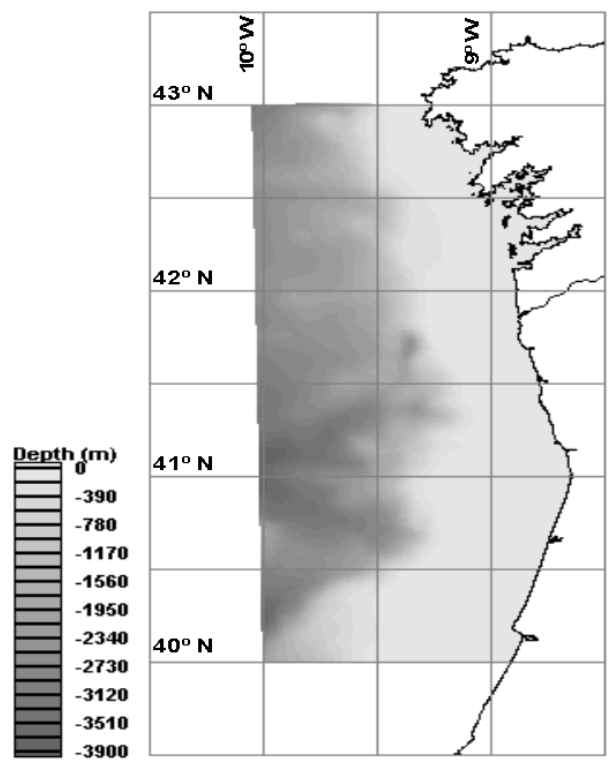

Fig. (6). 2DH hydrodynamic model: a) finite element mesh, b) bottom topography [10].

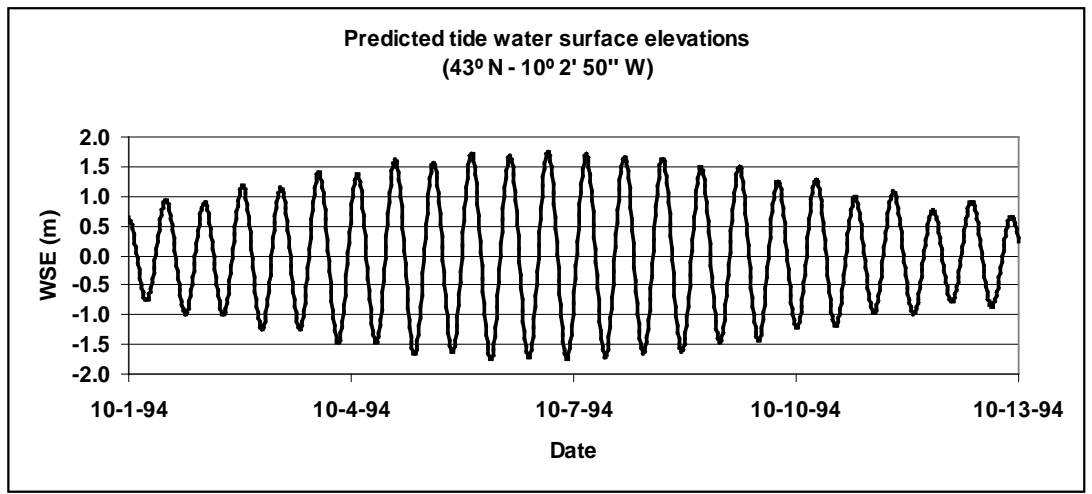

Fig. (7). Predicted tide water surface elevations at $43^{\circ} \mathrm{N}-10^{\circ} 2^{\prime} 50^{\prime}$ ' W from 1 to 13 October, 1994.

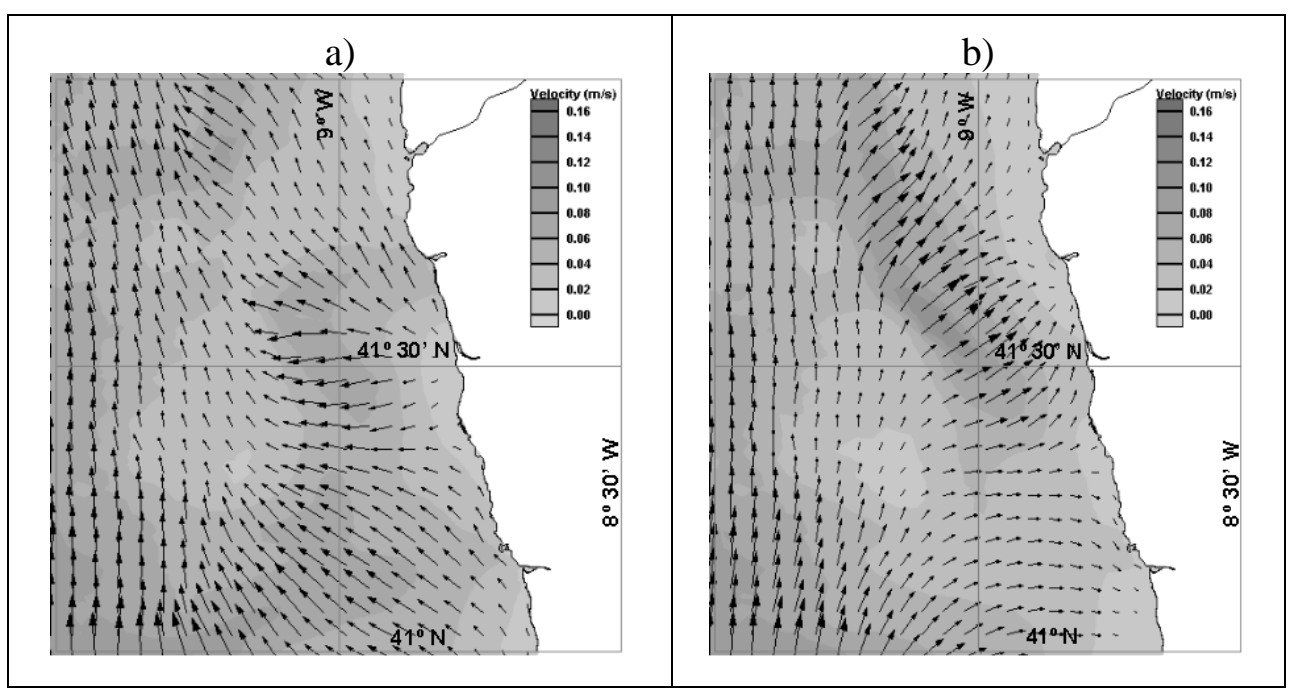

Fig. (8). Instantaneous maximum tide current velocities for: a) ebb, b) flood [10]. 
The hydrodynamic model results were used to calculate the daily residual tide current velocities during the accident period. Fig. (9) presents the results for each day of this period.

As shown in Fig. (9), the daily residual tide current velocities at the oil slick positions are lower than $2 \mathrm{cms}^{-1}$ (the results were similar for other days not shown in Fig. 9). The residual current shown is the result of the tide action on a spatially variable bathymetry and a very irregular coastline.

The wind therefore appears to have most influence on the oil transport process (compared with other types of current).

Once known the tide currents, $\vec{U}_{c}$, and the wind velocities, $\vec{W}$, the daily drift wind factor value must be established in order to quantify the velocities, $\vec{U}_{s}$, to be used in the Eulerian transport model (12). The net wave current velocity, $\vec{U}_{\text {wave }}$, was considered irrelevant. According to the positions observed for the oil slick, the daily $C_{w}$ value varies between 0.015 and 0.030 .
To show the general capabilities of the transport model, a simulation was carried out taking daily values calculated for $C_{w}$ within this interval $[0.015,0.030]$. Fig. (10) presents the calculated oil slick area, as a consequence of the calculated thickness and volume, at different oil slick positions.

This is a post-accident analysis in which the oil slick transport was primarily influenced by wind action, and where daily values were adopted for $C_{w}$ to reproduce the measured (known) oil slick positions. In the essential, it was solved an inverse problem that consisted in testing / validating the formulations for the parameters oil slick area and volume starting from the known (measured) oil slick positions.

Several simulations were carried out considering different $C_{w}$ values during the simulation period. The results obtained have shown a high sensitivity to this parameter. The Eulerian model results were further corroborated by calculating the volume of oil within the spatial integration domain (Fig. 11).

The time step used in the Eulerian approach of the hydrodynamic model was 0.5 hours. This component of the

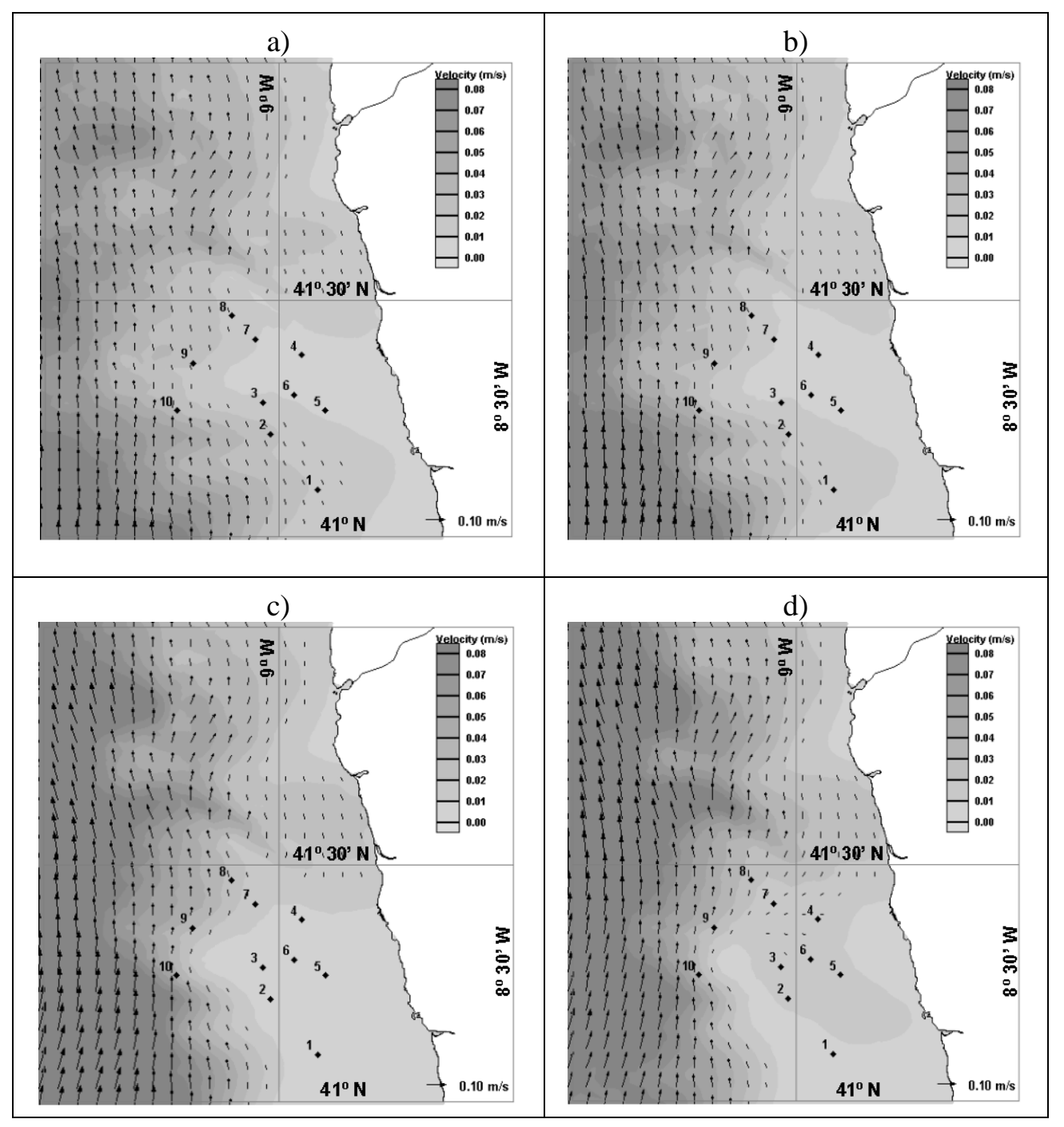

Fig. (9). Daily residual tide current velocities: a) 2 Oct 1994, b) 5 Oct 1994, c) 9 Oct 1994, and d) 12 Oct 1994 [10]. 


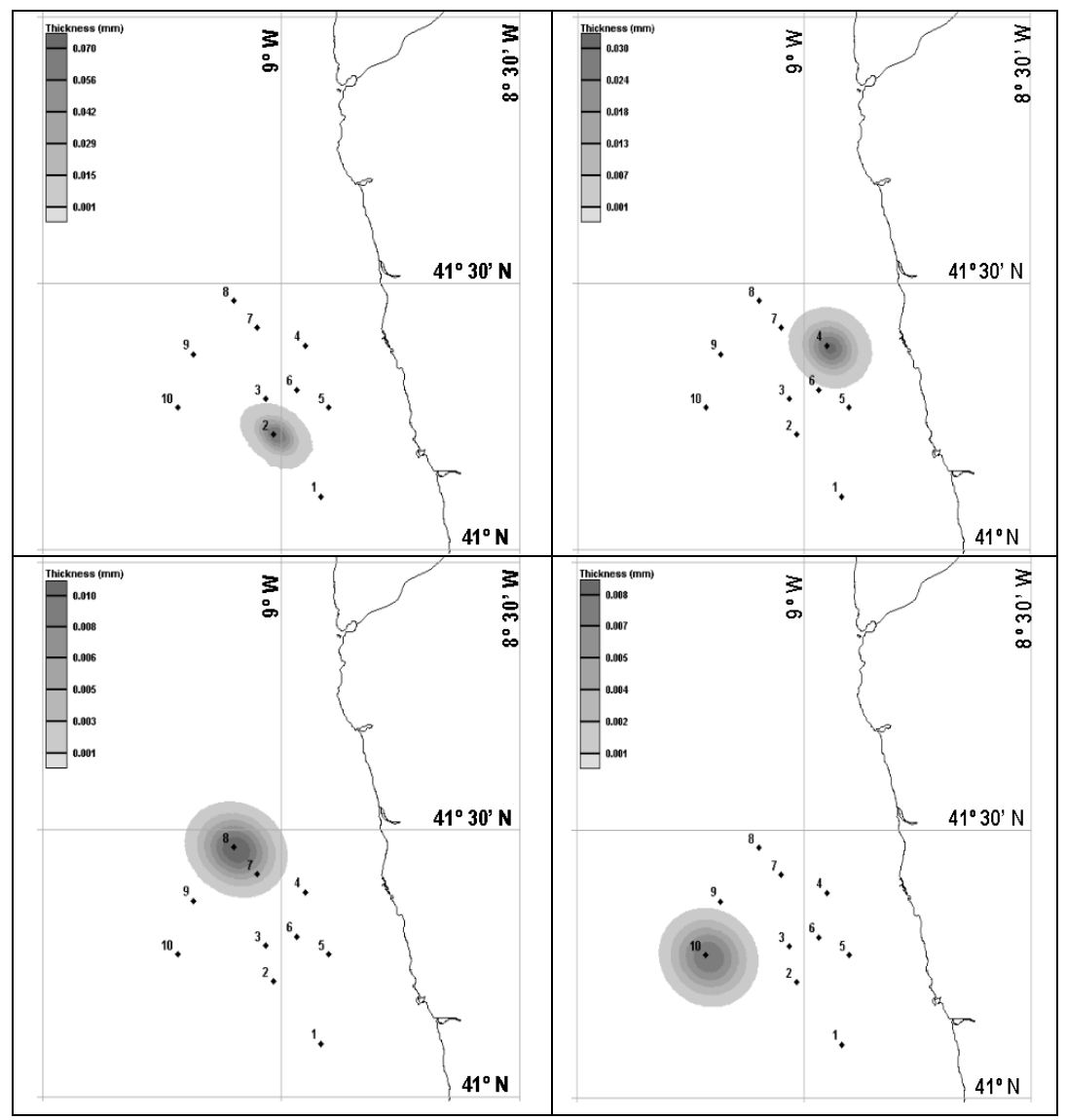

Fig. (10). Eulerian transport model results: oil slick dimension at different observed positions.

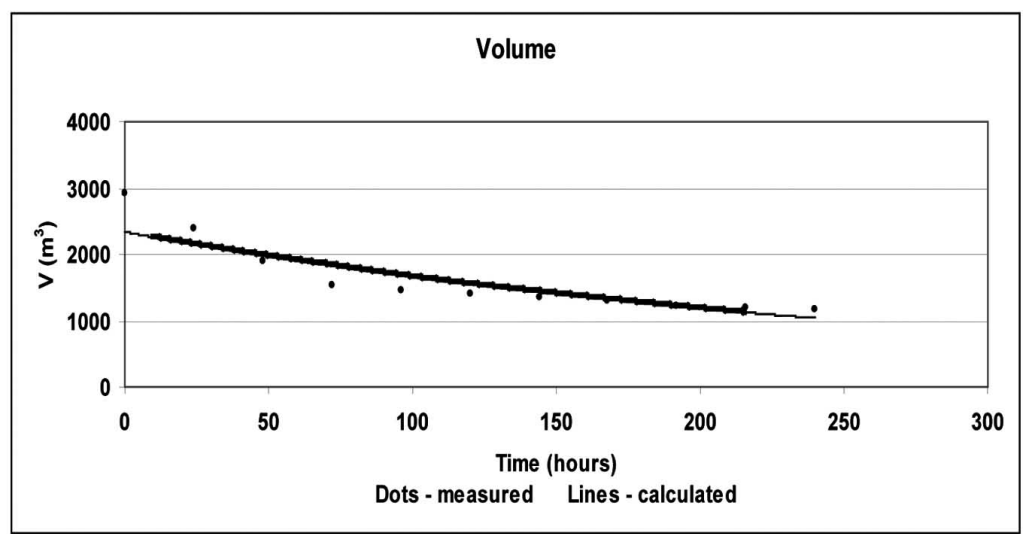

Fig. (11). Comparison between the observed oil volumes (points) and the calculated volumes.

simulation requires the most important parcel of the computational time. The transport components requires only a few minutes, both in the Lagrangian and Eulerian approaches.

The main differences between the two models used to simulate the "Cercal" oil spill accident are: (i) in the Lagrangian model a constant value for the wind drift factor was adopted and in the Eulerian approach daily values were considered, (ii) in the Eulerian approach tide currents were considered and in the Lagrangian one they were neglected.

\section{"New World" Accident}

The computational structure developed has been utilized to reproduce the evolution of the spilling of 30000 tons oc- curred on 21 December 1994 in the Atlantic Ocean (coordinates $36^{\circ} 12^{\prime} \mathrm{N}$ and $13^{\circ} 00^{\prime} \mathrm{W}$, approximately). Since it occurred in an open ocean area only the Lagrangian model was applied.

Numerical results (continuous blue line) were compared with the ones obtained by the Portuguese Air Force and also reproduced in Fig. (12) (isolated red points). The maximum deviations obtained between the calculated and real positions are less than 4 miles in latitude and 20 miles in longitude.

From the $1^{\text {st }}$ of January on we don't have measures. However, numerical computations show that the pollutant cloud would reach Porto Santo 10 days after, as has been 


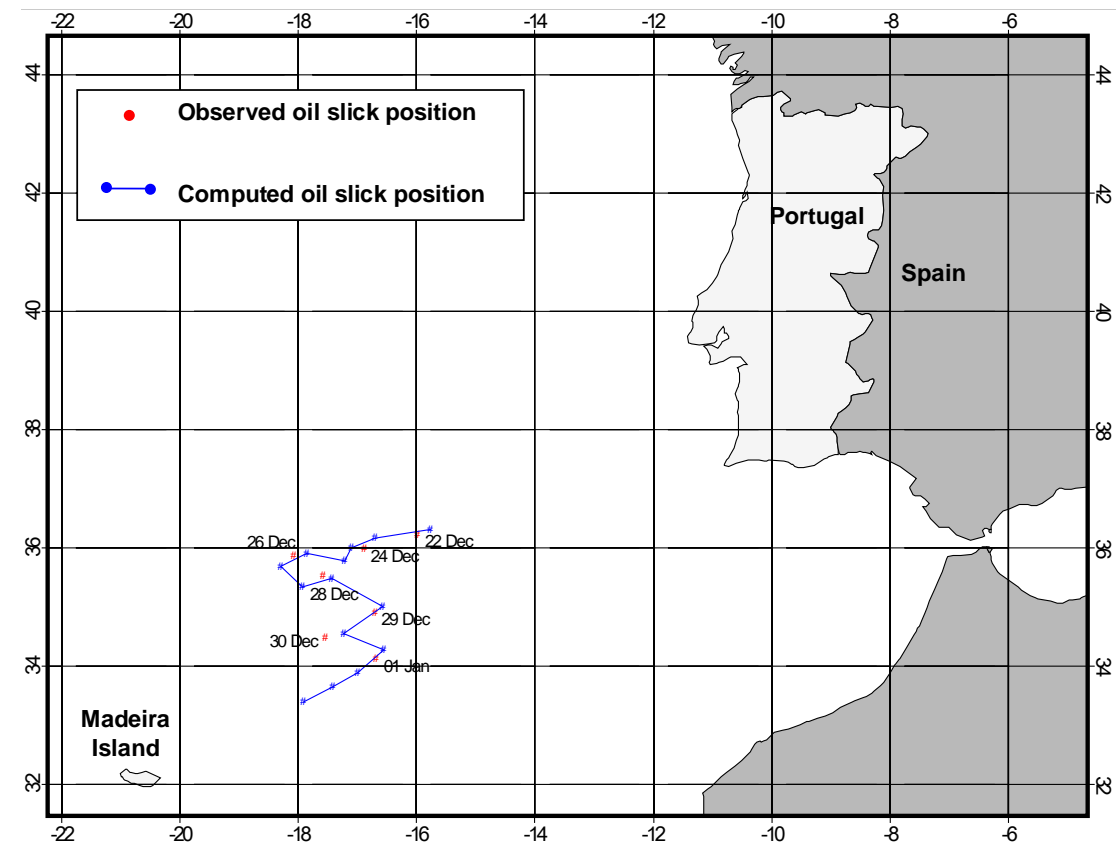

Fig. (12). Spatial and temporal evolution of the spilling originated from the N/T "New World".

proved by the hydrocarbon residues found in the island at the $10^{\text {th }}$ of January 1995. Other comparisons are shown in Table 3.

Also in this case, the results shown in Fig. (12) and Table 3 can be considered satisfactory. Therefore, the computational structure presented above seems to be adequate and useful:

- to simulate hydrocarbon spills in different Portuguese sensitive estuaries and other identified coastal regions;

- to follow a cloud of pollutants in any location of the Atlantic Ocean, particularly within the Portuguese EEZ; and

- to help guide the ships combating pollution, and with the goal of obtaining reports that support a decision, on the distribution/localization of the means of combating hydrocarbon pollution.

\section{A DISCUSSION ON STRENGTHS AND WEAK- NESSES OF NUMERICAL SIMULATIONS}

Numerical models are intrinsically able to predict the evolution and behaviour of oil spilled at sea, regardless of the atmospheric conditions, hence the vast interest in them. Mathematical modelling is thus a very powerful tool for management assessment after an oil spill accident, particularly for determining preventive measures and to help monitoring accident evolution.

The latest information technologies have provided us with new tools and different strategies in the field of environmental management that are capable of efficiently processing the great quantity of information needed to support accidental hydrocarbon spill management.

These modelling tools are now of paramount interest in the forecasting of oil slick evolution at sea as they allow measures to mitigate the negative impacts associated with hydrocarbon spills to be put in place.

A numerical model may also represent an important tool for contingency planning and facilitates on-scene commanders in decision-making concerning the use of different countermeasure techniques (mechanical recovery equipment, burning, scattering, etc.) during oil spill combat operations.

The accidents with the "Aragon" and the "New World" tankers have demonstrated the importance of an oil spill simulation model to forecast the short- and long- term behaviour, and the evolution of the oil slick.

When integrated with Geographical Information Systems tools, the information yielded by the models' simulations can be analysed easily and appropriately.

However, numerical models should be used with care, as they have weaknesses. In coastal areas the use of the wind characteristics only is not sufficient for oil spill fate prediction, as the general circulation is constrained by the coast and not directly related to wind direction. The presented models chain have the capability to predict oil spill fate also in this area, but the hydrodynamic model should be used to predict also wind driven current to be applied in either the Lagrangian or Eulerian models.

Concerning the surface oil slick transport, once the plume was transported off the coast due to wind action during the accident both Lagrangian and Eulerian models presented a reasonable performance. However, in situations where the plumes are transported into the coast, tidal currents can get a more important role in the oil slick transport and it is expected that the Eulerian model becomes more accurate.

The effect of using depth averaged currents instead of surface currents, that are those really driving the oil mass transport, is an important topic that should be addressed. 
Table 3. Volume and Geometry Changes of the Pollutant Cloud Originated from the N/T "New World"

\begin{tabular}{|c|c|c|c|c|c|c|c|c|}
\hline Day & $\begin{array}{l}\text { Volume } \\
\left(m^{3}\right)\end{array}$ & $\begin{array}{c}\text { Volume } \\
\left(m^{3}\right)\end{array}$ & $\begin{array}{c}\text { Relative } \\
\text { Error }\end{array}$ & $\begin{array}{l}\text { Area } \\
\left(\mathrm{km}^{2}\right)\end{array}$ & $\begin{array}{l}\text { Area } \\
\left(\mathrm{km}^{2}\right)\end{array}$ & $\begin{array}{l}\text { Relative } \\
\text { Error }\end{array}$ & $\begin{array}{c}\text { Radius } \\
(\boldsymbol{K m})\end{array}$ & $\begin{array}{c}\text { Thickness } \\
(\mathrm{mm})\end{array}$ \\
\hline & Real & Calculated & (\%) & Real & Calculated & (\%) & Calculated & Calculated \\
\hline 22-Dec & 29100 & 28999 & -0.3 & 28.0 & 27.9 & -0.3 & 2.98 & 1.038 \\
\hline 24-Dec & 24370 & 24048 & -1.3 & 87.0 & 85.9 & -1.3 & 5.23 & 0.286 \\
\hline 28-Dec & 14100 & 14580 & 3.4 & 238.0 & 245.8 & 3.3 & 8.85 & 0.059 \\
\hline 30-Dec & 12600 & 13172 & 4.5 & 320.0 & 339.6 & 6.1 & 10.4 & 0.038 \\
\hline
\end{tabular}

Using 3D models, we hope to obtain useful insight on this matter. This research is expected to commence shortly.

\section{CONCLUSIONS}

Numerical models are able to predict the evolution and behavior of oil spilled at sea, independently of the atmospheric conditions. In preventive terms, these models could even represent the only method of planning the implementation of means of combating pollution at sea.

The computational model described here is based on either a $2 \mathrm{DH}$ or a quasi-3D (hydrostatic approximation) hydrodynamic model, on a Lagrangian approach and a simplified $2^{\text {nd }}$ degree equation for the cloud radius, or on a Eulerian surface oil slick transport model, and on classical empirical formulations for spreading and weathering processes. It proved to be satisfactory for modelling oil spill accidents in open ocean areas.

Some widely applied expressions for oil spill characteristics (evaporation loss, vertical dispersion, emulsification, volume and area) showed its suitability for modelling both the "Cercal" and the "New World" oil spills.

It is shown, in the "Cercal" case, that the wind forcing is the main contributor for the surface transport of the pollutant oil mass. It could be argued that both the tidal currents and the net wave velocities are of $2^{\text {nd }}$ order relatively to the wind driven currents that are in general (but not always) the main contributor. Therefore, for forecasting purposes, special care must be taken in the prediction of the $C_{w}$ wind drift factor. Furthermore, wind characteristics (velocity and direction) must be properly recorded (or anticipated).

\section{REFERENCES}

[1] GESAMP - IMCO/FAO/UNESCO/WNO/AIEA/UN/UNEP Joint Group of Experts on the Scientific Aspects of Marine Pollution, "The evaluation of the hazards of harmful substances carried by ships", Report and Studies no. 35, p. 150, 1989.

[2] C. Brekke, and A.H.S. Solberg, "Oil spill detection by satellite remote sensing", Remote Sensing of Environment, vol. 95, no. 1, pp. 1-13, 2005.

[3] M.N. Jha, J. Levy, and Y. Gao, "Advances in remote sensing for oil spill disaster management: State-of-the-Art sensors technology for oil spill surveillance", Sensors, vol. 8, pp. 236-255, 2008. (www.mdpi.org/sensor).

[4] H.D. Kuipers, "SMOSS - A Simulation Model for Oil Slicks at Sea", Delft University of Technology and North Sea Directorate Ministry of Transport and Public Works, Rijswijk, The Netherlands, 1981.
[5] National Research Council (NRC), "Committee on Effectiveness of Oil Spill Dispersants Using Oil Spill Dispersants on the Sea", USA, National Academy Press, 1989.

[6] A.G.L. Borthwick, and S.A. Joynes, "Laboratory study of oil slick subjected to nearshore circulation", Journal of Environmental Engineering, vol. 118, no. 6, pp. 905-922, 1992.

[7] L.Y. Yuan, Z. Fang, and S.M. Chen, "Numerical Modelling of Oil Slick Motions by a Fully Dynamic Model", Henan Science and Technology Press, China, 1992.

[8] P. Sebastião, and C. Guedes Soares, "Modeling the fate of oil spills at sea", Spill Science \& Technology Bulletin, vol. 2, no. 2/3, pp. 121-131, 1995.

[9] J.S. Antunes do Carmo, and M. Costa, "Modelling of oil spill evolution in estuaries and coastal regions", In: Proceeding of $2^{\text {nd }}$ International Conference on Oil Spill, 2000, pp. 63-72.

[10] J.L.S. Pinho, J.S. Antunes do Carmo, and J.M.P. Vieira, "Numerical Modelling of Oil Spills in Coastal Zones. A Case Study", In: Proceeding of $3^{\text {rd }}$ International Conference on Oil Spill, 2002, pp. $35-45$.

[11] E. Comerma, M. Espino, P. Daniel, A. Doré, and F. Cabioch, “An update of an oil spill model and its application in the Bay of Biscay: the weathering processes", In: Proceeding of $3^{\text {rd }}$ International Conference on Oil Spill, 2002, pp. 13-22.

[12] J.L.S. Pinho, J.M.P. Vieira, and J.S. Antunes do Carmo, "Mathematical modelling of oil spills in the Atlantic Iberian coastal waters", In: Proceeding of $4^{\text {th }}$ International Conference on Oil Spill, 2004, pp. 337-347.

[13] F. Betancourt, A. Palacio, and A. Rodriguez, "Effects of the mass transfer process in oil spill", American Journal of Applied Sciences, vol. 2, no. 5, pp. 939-946, 2005.

[14] P. Sebastião, and C. Guedes Soares, "Uncertainty in predictions of oil spill trajectories in a coastal zone", Journal of Marine Systems, vol. 63, nos. 3-4, pp. 257-269, 2006.

[15] M. Nazir, F. Khan, P. Amyotte, and R. Sadiq, "Multimedia fate of oil spills in a marine environment - An integrated modelling approach", Process Safety and Environmental Protection, vol. 86, no. 2, pp. 141-148, 2008.

[16] S.-D. Wang, Y.-M. Shen, Y.-K. Guo, and J. Tang, "Threedimensional numerical simulation for transport of oil spills in seas", Ocean Engineering, vol. 35, nos. 5-6, pp. 503-510, 2008

[17] W.J. Guo, and Y.X. Wang, "A numerical oil spill model based on a hybrid method", Marine Pollution Bulletin, vol. 58, no. 5, pp. 726734, 2009.

[18] WES-HL, "Users Guide to RMA2 Version 4.3", US Army Corps of Engineers - Waterways Experiment Station Hydraulics Laboratory, Vicksburg, USA, 1996.

[19] G. Mellor, "Users Guide for a Three-Dimensional, Primitive Equation, Numerical Ocean Model", Princeton University, Princeton, USA, 1998.

[20] J.L.S. Pinho, "Application of Mathematical Modelling on the Study of the Hydrodynamics and Water Quality in Coastal Regions", $\mathrm{PhD}$ thesis, University of Minho, Portugal (in Portuguese), 2001.

[21] A. Blumberg, and G.L. Mellor, "A description of a threedimensional coastal ocean circulation model", In: TreeeDimensional Coastal Ocean Models, N.S. Heaps Ed., American Geophysical Union, Washington, D.C., 1997, pp. 1-16. 
[22] IMO - International Maritime Organization, "Manual on Oil Pollution, section IV Combating Oil Spills", IMO Publication no. 569 88.11, London, 1988.

[23] I. Buchanan, and N. Hurford, "Methods for predicting the physical changes in oil spilt at sea", Oil and Chemical Pollution, vol. 4, no. 4, pp. 311-328, 1988.
[24] D. Mackay, I. Buist, R. Mascarenhas, and S. Petersen, "Oil Spill Processes and Models", Technical Report EE-8, Environmental Protection Service, Canada, 1980.

[25] JPL, "A Collection of Global Ocean Tide Models", Jet Propulsion Laboratory, Physical Oceanography Distributed Active Archive Center Pasadena, CA, 1996.

Received: April 23, 2010

(C) do Carmo et al.; Licensee Bentham Open.

This is an open access article licensed under the terms of the Creative Commons Attribution Non-Commercial License (http://creativecommons.org/licenses/by-nc/3.0/) which permits unrestricted, non-commercial use, distribution and reproduction in any medium, provided the work is properly cited. 